\title{
Business Intelligence for Human Capital Management
}

\author{
Maria José Sousa, ISCTE - Instituto Universitário de Lisboa, Lisbon, Portugal \\ D https://orcid.org/0000-0001-8633-4199 \\ Ivo Dias, Universidade Europeia, Lisbon, Portugal \\ https://orcid.org/0000-0001-6387-0722
}

\begin{abstract}
This article presents the results of an exploratory study of the use of business intelligence (BI) tools to help to make decisions about human resources management in Portuguese organizations. The purpose of this article is to analyze the effective use of BI tools in integrating reports, analytics, dashboards, and metrics, which impacts on the decision making the process of human resource managers. The methodology approach was quantitative based on the results of a survey to 43 human resource managers and technicians. The data analysis technique was correlation coefficient and regression analysis performed by IBM SPSS software. It was also applied qualitative analysis based on a focus group to identify the impacts of business intelligence on the human resources strategies of Portuguese companies. The findings of this study are that: business intelligence is positively associated with HRM decision-making, and business intelligence will significantly predict HRM decision making. The research also examines the process of the information gathered with BI tools from the human resources information system on the decisions of the human resources managers and that impacts the performance of the organizations. The study also gives indications about the practices and gaps, both in terms of human resources management and in processes related to business intelligence (BI) tools. It points out the different factors that must work together to facilitate effective decision-making. The article is structured as follows: a literature review concerning the use of the business intelligence concept and tools and the link between BI and human resources management, methodology, and the main findings and conclusions.
\end{abstract}

\section{KEYWORDS}

Business Intelligence, Decision making, Human Resources Management, Human Resources Metrics

\section{INTRODUCTION}

In the present context of increasing globalization, rapid technological advancement, and the move towards a knowledge-based economy, companies need to become technologically empowered to act in competitive environments.

This article presents the BI concept analysis applied to human resources management, identifying practices and dimensions that are crucial for the decision-making process of organizations. The main contribution of the research is the proposal of a model that applies the BI tools to the Human resources management effective decision-making process. 
Business Intelligence helps organizations to use the information to gain a competitive advantage over competitors. It combines people skills, technologies, and business processes to make better strategic business decisions. The technologies and applications include data management methods for planning, collecting, storing, and structuring data into data warehouses and data marts as well as analytical tasks for querying, reporting, visualizing, generating online active reports, and running advanced analytical techniques for clustering, classification, segmentation, and prediction. A data warehouse focuses on enterprise-wide data, and data mart is restricted to a single process or a department, such as Human Resources (HR) department.

BI helps organizations to face growing difficulties in analyzing essential data to manage organizational changes. These changes have had a significant impact on the role of the human resources management (HRM), increasing strategic emphasis and aligned with business strategies (Mishra \& Akman, 2010; Park et al., 2004). It is crucial to be able to meet the market needs with well-qualified employees (Hustad \& Munkvold, 2005).

IT have allowed increased flexibility, speed, and quality of decision (Ball, 2001; Kashive, 2011; Mishra \& Akman, 2010) in Human resources Management. Today, organizations wishing to compete in the knowledge-based economy can use IT as a powerful tool to strengthen their capacity and also management activities (Hempel, 2004; Snell et al., 2002; Tansley \& Watson, 2000; Teo et al., 2007). Mishra and Akman (2010) note that organizations competitive advantage is seeking to implement targeted actions for the implementation of IT in the critical area of the HR function.

Organizations usually develop and implement information systems to address specific business needs like as to help decision-makers resolve complex problems, respond to crises, and seize opportunities needs (Martinsons \& Chong, 1999). An important innovation within the HRM function is the use of IT, which has led to the development of computer-based human resources information systems (HRIS). Hendrickson (2003) observes that HRIS is the 'backbone' of contemporary HRM function.

HRIS is a concept which utilizes the development of IT for effective management of the HR functions (Hendrickson, 2003). This kind of system can acquire, store, manipulate, analyze, retrieve, and distribute information (Haines \& Petit, 1997; Hendrickson, 2003; Kavanagh et al., 1990; Kashive, 2011; Tannenbaum, 1990). It combines two critical resources in a knowledge-based economy which can affect the overall performance of a business: people and information (Martinsons, 1994; O’Daniell, 1999).

\section{BUSINESS INTELLIGENCE}

\subsection{Business Intelligence Concept}

The concept Business Intelligence (BI) was reported by Hans Peter Luhn (1896-1964) to be defined as "the ability to grasp the relations of the facts presented to guide the action to the desired goal." Howard Dresner For (1989) considers the BI as an umbrella term to describe "concepts and methods to improve business decision-making supported on support systems. The idea includes the architecture, tools, databases, applications, and methodologies (Raisinghani, 2004). It 0llow interactive access to the data (sometimes in real-time) and provides to managers and analysts the ability to conduct a proper analysis (Turban et al., 2008). In general, the BI is the evolutionary process in which the data is subject to its transformation into information and then into knowledge. The data represent the raw material (OLTP), which after selection, processing and incorporation of summarization techniques (ETL) are stored in databases and tables themselves analysis system (Data Warehouse), giving the various stakeholders knowledge more extended data through the multiple analytical techniques system and visualization.

Today's highly competitive and rapidly changing business environment requires agility from organizations and high-quality decisions. With the right capabilities, BI plays an essential role to 
enhance organization's skills to predict changes in several domains can be either the choice of surviving or thriving (Alhyasat et al., 2013; Isik et al., 2013; Vuksi et al., 2013).

Business Intelligence has become a strategic initiative (Watson \& Wixom 2007) and is now recognized as instrumental in driving business effectiveness and innovation. It is considered to be a process by which an organization systematically gathers, manages, and analyzes essential information (Skyrius et al., 2013). This information helps to understand the customers, and the competitors, to facilitate organizations' planning and operational decisions (Negash, 2006).

BI systems are defined as specialized and analytical tools for data analysis, query, and reporting, that support organizational planning and decision-making. It enhances the performance of a range of business processes, intending to improve the timeliness and quality of the input to the decision process (Elbashir et al., 2014; Negash, 2006) and create new opportunities to improve the performance (Kesti, 2013).

\subsection{Business Intelligence Tools}

The BI system consists of several tools which work in as integrated elements. The central literature uses the following classification (Kapoor et al., 2010): data management, analytics, business performance management, and information delivery.

Data Management includes components as data warehouses, data marts, and online analytical processing (OLAP). The main goal is to manage the development, implementation, and operations of a data warehouse or data mart, including extraction, transformation, cleaning, and loading of data from different sources. It also includes meta-data management, security management, backup and recovery, and data distribution. The past data to answer questions, such as - What happened? Why did it happen? For example, the employees" recent data can shed light on employee attrition fluctuations and factors that were responsible for the variations.

The Advanced Analytics sub-system includes analytic functions based on statistics, data mining, forecasting, predictive modeling, predictive analytics, and optimization. Data mining is an extension of statistical techniques such as classical and artificial intelligence. Analytical methods are generally applied to relatively small size random sample data specifically collected to validate a hypothesis, and the methods conform to a set of assumptions about the population. These techniques can be regarded as discovering information by exploration (Kim, 2002; Tan, Steinbach \& Kumar, 2006; Shmueli, Patel \& Bruce, 2010). The Advanced Analytics subsystem enables organizations to answer questions, such as - What if the trend continues? What are the best actions to take? What will happen as a result of these actions?

The Business Performance Management consists of processes for strategic goals and objectives, performance measurement and mentoring, analyzing performance, and making decisions to improve business performance.

The Information Delivery gives the business users the ability to access reports and continuously monitor organizational performance at enterprise and lower levels. It is possible to monitor critical activities such as trends, metrics, and KPIs in easy-to-understand designs, such as configurable information portals, scorecards, and dashboards.

\section{HUMAN RESOURCES MANAGEMENT AND BUSINESS INTELLIGENCE}

\subsection{Human Resources Management}

In today's competitive and complex business environment, the role of Human Resource (HR) is continually changing. HR, with its increasing alignment to core business and integration to the bottom line, is a reflection of the constantly changing nature of HR function.

Being responsive to globalization, demographic and technological change, and turbulent, competitive, and complex environment of business, HR itself has been changing dramatically. A 
transformational journey from the conventional role of 'administrative expert' (Ulrich 1997 cited in Reilly 2006, p. 8) to the evolving and fostering function of strategic HR partner describes the value contribution of the HR function. More precisely, HR goes strategic and becomes more businessintegrated. This intended reorientation contributes HR not only to play a critical role in overall strategic planning of the business but also to act as a messenger to clarify and direct employees about the desired goal of the organization.

The evolution of HR function leads to its integration into organizational strategy and this vertical integration of HR with other disciplines of business involves HR professionals' direct participation in strategic planning and implementation of corporate mission, values, culture, strategy, and goal. This kind of direct involvement of the HR leader with core business planning reveals the new acceptance of $\mathrm{HR}$ as a valued contributor in business.

Aligning HR practices to a strategy which means that each investment of HR discipline must reflect the policy and 'realities of the customer' (Ulrich et al., 2009, p. 29). More precisely, in today's organizations all HR activities, including selection and recruitment, training and development, reward and compensation systems, are designed and practiced such an effective way which must exhibit HR's alignment with business strategy.

\subsection{Business Intelligence as a Driver for Human Resources Strategic Management}

Business Intelligence is a field that combines people skills, technologies, applications, and business processes to make better strategic and tactical business decisions. The technologies and applications include data management methods for collecting, storing, and structuring data into data warehouses or data marts as well as performing analytical queries, reporting, visualizing, and using analytical techniques for prediction. A data warehouse focuses on the extensive data from the whole company, and data mart is restricted to a single process or a department, such as human resources (HR) department.

HR data is extensive in its variety, so an effective HRIS must address a range of administrative, statutory, functional, and technological requirements to support organization-wide planning and decision-making. The data provided by Information System Human Resources (HRIS) enable HR specialists to become relevant partners, both for specialists from other management functions, such as for top managers. (Mishra \& Akman, 2010; Singh et al., 2011). Becker and Huselid (2006) have identified the following variables to assess the benefits of HRIS: Workforce Planning; Employee Benefits Administration; Payroll Administration; Recruitment; Induction; Orientation and On-boarding; Training and Development; Skills Management; Personnel Administration; Time Management; Travel Management; Personnel Cost Planning; and Performance Appraisal.

Over the last two decades, the number of firms investing in HRIS and their depth of applications within the organizations has increased. Thus, HRIS implementation success has emerged as a significant challenge for organizations (Ball, 2001; Lippert \& Swiercz, 2005; Kashive, 2011). There is a consensus that these systems contribute, in a very significant way, to the development of HRIS.

Teo, Lim, and Fedric (2007) refer that for organizations which have adopted HRIS, the investments are small and usually address tactics and administration (e.g., transaction processing for payroll and benefits administration) with focus on administrative efficiency, rather than strategy (e.g., in knowledge management and workforce planning) oriented to strategic applications that make organizations more productive and competitive.

According Lengnick-Hall and Moritz (2003), HIRS has developed through three main ways, from the most straightforward way, through provision of information, considering an intermediate level with the automation of transactions, to form more complex and sophisticated that modifies how the HR function is performed and becomes a strategic business partner (Kashive, 2011).

When we examine the benefits of HRIS found two extreme possibilities - a regulatory approach and a strategic approach - and if both are oriented to promote organizational efficiency and effectiveness - only a strategic approach to HRIS allows for greater competitiveness (Beadles et al., 2005). As a consequence, HRIS have evolved into sophisticated IT solutions designed to manage a wide variety 
of human resource data and to provide analytical tools to assist management in HR decision-making (Hendrickson, 2003).

An HRIS can be designed in different ways, depending on the perceptions and knowledge of those involved and therefore, the role of the HR function. It may be used for automating. HRIS can vary from being just a specific 'stand-alone' personnel software package for the use of stored, personal data, to a system which operates beyond the usual functional HR department boundaries.

The replacement of the intervention of HR specialists and the automation of processes in the current HRM activities can increase efficiency through HR information management allowed by HRIS (Kashive, 2011; Mishra \& Akman, 2010; Tansley \& Newell, 2007) as well as provide essential information for decision-making on issues strategic, promoting the value generated for the organization by HRIS (Beadles II et al 2005).

We are facing a new paradigm in which, in addition to efficiency gains in the HR function, are present the necessary conditions for HR specialists assume a unique role in the relationship established with experts from other management functions as well as the management top, the achievement of strategic organizational objectives (Tansley \& Newell, 2007).

\section{METHODOLOGY}

This research was based on a survey research design method. It involved a self-designed questionnaire in collecting data. The sample size for the study was 43 clients of a human resources software company in Portugal which send a massive email to their almost 1000 clients to disseminate the questionnaire and to help gather responses. Convenience sampling method was used. The convenience sampling is a basic sampling design, which allows equal representation and selection of samples.

The subject's fill-in the questionnaire online and instructions on how to fill the survey was given on the questionnaire first page. Confidential treatment of information was assured, and questions were ranged from 7-point scale in the following pattern. Strongly agree $-7 \&$ Disagree -1 .

For the analyses of the impacts of business intelligence on the human resources strategies, from Portuguese companies, three focus groups were realized to create dynamic discussions about that issue. The goal was that qualitative analysis provided by the focus groups might add essential insights to the research helping to the interpretation of the results found.

\subsection{Hypothesis}

In this study, it has analyzed the expectations of two main stakeholders comprising of Human Resources Managers and Human Resources Technicians. This is measured in terms of the following parameters:

(i) HR Managers satisfaction with information gathered from the HRMIS by business intelligence tools regarding their decision-making process.

(ii) HR Technicians satisfaction with the quality of decisions made by HR managers according to the business tools used.

In this context and aligned with the literature review, two hypotheses were defined:

H1: Business Intelligence is positively associated with HRM decision making.

$\mathrm{H} 2$ : Business Intelligence will significantly predict HRM decision making.

The methods of data analysis to verify these hypotheses were the correlation coefficient and regression analysis performed by SPSS software, as explained later in this paper. 


\section{FINDINGS}

\subsection{Correlation Analysis}

H1: Business Intelligence is positively associated with HRM decision making.

Pearson correlation table has developed for finding association and testing first hypothesis of Business Intelligence as independent variables and decision making as dependent variable, the below Table 1 is stating human resources managers satisfaction with decision-making variable versus BI variable reporting have correlation $(\mathrm{R})=38 \%$, analysis $\mathrm{R}=63 \%$, and measures/metrics $\mathrm{R}=31 \%$ positive Correlation is significant at the 0.01 , dashboard has $60 \%$ negative correlation with 0.01 level . Technicians satisfaction with the quality of decisions: reporting $\mathrm{R}=14$ with 0.05 level, analysis is $86 \%$, measures/metrics has $87 \%$ positive correlation with 0.01 level and dashboard having a negative correlation with 93 at 0.01 level. Technicians expressed satisfaction with the decision making based on BI tools; all variables have more than $50 \%$ correlation at the 0.01 level. Majority of the variables are having positively significant in that case $\mathrm{H} 1$ can be accepted.

\subsection{Regression Analysis}

$\mathrm{H} 2$ : Business Intelligence will significantly predict HRM decision taking.

For fulfilling the second Hypothesis, below Regression analysis, is generated. There were done regression analysis using SPSS 20 version and applied enter method for proving the second Hypothesis. Majority of the independent variables are having reasonable estimating indications while we are comparing with HR Manager satisfaction with decision making correlates with $78 \%$, and R Square is 61 . If $\mathrm{R}$ Square exceeds $50 \%$, it indicates that there is a good predictor. All dependent variables have strong associations, that is a correlation, $\mathrm{R}$ square, and Adjust $\mathrm{R}$ square strongly recommends that maximum independent variables are good predictors for estimating dependent variables. It is possible to state that BI can significantly effectively predict the HRM decision (Table 2).

Table 1. Multiple regression analysis

\begin{tabular}{|l|l|l|}
\hline \multicolumn{1}{|c|}{ Business Intelligence } & \multicolumn{1}{c|}{ HR Managers } & \multicolumn{1}{c|}{ HR Technicians } \\
\hline Reporting & $.380^{* *}$ & $-.143^{*}$ \\
\hline Analysis & $.631^{* *}$ & $.864^{* *}$ \\
\hline DashBoard & $-.605^{* *}$ & $-.938^{* *}$ \\
\hline Measures/Metrics & $.313^{* *}$ & $.875^{* *}$ \\
\hline
\end{tabular}

**. Correlation is significant at the 0.01 level (2-tailed), *. Correlation is significant at the 0.05 level (2-tailed).

Table 2. Multiple regression analysis

\begin{tabular}{|l|l|l|l|l|l|l|l|l|}
\hline \multirow{2}{*}{$\begin{array}{c}\text { Dependent } \\
\text { Variables }\end{array}$} & Constant & Reporting & Analysis & Dashboard & $\begin{array}{c}\text { Measures/ } \\
\text { Metrics }\end{array}$ & $\begin{array}{c}\text { R } \\
(\%)\end{array}$ & $\begin{array}{c}\text { R square } \\
(\%)\end{array}$ & $\begin{array}{c}\text { Adjusted } \\
\text { R square } \\
(\%)\end{array}$ \\
\hline HR Managers & -12.67 & $3.45^{* * *}$ & $0.35^{*}$ & $-0.61 * * *$ & $-0.32 *$ & 78 & 61 \\
\hline HR Technicians & 4.51 & -0.04 & $.41^{* *}$ & $-.43^{* * *}$ & $0.37 * * *$ & 96 & 93 & 60 \\
\hline
\end{tabular}




\subsection{Implications of BI Applied to Human Resources Management Strategies in Portuguese Companies}

The focus groups provided a very detailed description and examples of the practical dimensions that contribute to a better decision-making process based on the BI tools. Therefore, the mains results that emerged from the focus group state that the BI process can allow to analyze the workforce of an organization and make a strategic decision on the workforce planning and prediction in terms of:

- Workforce planning, using workforce demographic data, through the use of predefined reports to analyze headcount development, turnover rates, and workforce composition. This information can be linked to headcount planning, budgeting, and critical talent processes, such as recruiting and learning.

- Workforce cost planning and simulation, providing access to a broad range of data to facilitate simulated planning scenarios and enable continuous monitoring of performance.

- Analytics and measures help to analyze HR processes, such as payroll, employee administration, time management, and benefits and also organizational structures, relationships, and attributes of jobs and positions.

- Also helps to analyze talent management, employee skills, and qualifications. Helping to explain if succession programs prepare employees to assume key positions - and ensure continuity of operations and analyze the cost-effectiveness of employee compensation programs.

- Strategic Alignment, ensuring that all business activities are in line with the strategic goals of the organization.

\subsection{How Portuguese HRM Departments Applies Business Intelligence Tools}

In the global competition and the connected world, decision-making in organizations has become increasingly complex and depending on accurate data. This situation creates challenges for Portuguese organizations and Human Resources Managers because they are under pressures to answer quickly to dynamic conditions of the market. The organization tries to redesign their structures, redefine the practices and the business processes. Business Intelligence and analytics are tools that can help the decision-making process in those contexts. Literature shows that most of the organizations that have successfully implemented BI can make decisions quickly and with more accuracy. These organizations have better and faster access to the key activities and processes that the organizations and their functional departments must pursue to meets its goals.

According to Portuguese Human Resources Managers, the Key Performance Indicator - KPI - is the leading management tool to analyses the strategic objectives in HRM. However, the vast volumes of data and the difficulties due to their dispersion in an organization make their integration and processing difficult for decision-making. The literature (Wawer and Muryjas, 2011) also shows that the ability of the human mind is now insufficient to make optimal business decisions in the era of the growing amount of information and the complexity of analytical requirements. Business intelligence then becomes an essential tool which combines the business and information technology (IT) issues, delivering valuable information to decision-makers, through tools as simulations and scenarios which can help the optimization of organization development and also to forecasting business results and customer behaviors.

Analyzing the Portuguese case in light of the Laursen and Thorlund (2010) scenarios it's possible to find the same orientation and alignment of BI on the strategic level: 1) BI and HR strategy separation - BI does not deliver data to the strategic level, it is only used to answer some questions on the operational level; 2) Passive support for the strategy by BI - the only role of BI is to produce reports to support strategy performance; 3) Dialogue between BI and HR strategy - the results of BI analyses may modify the strategy; 4) Interpenetration of BI and HR strategies - the results of BI analytics are treated as a strategic resource of an organization, which determines the HRM strategy. 
To conclude the analysis of the Portuguese context, it is possible to say that HRM supported by BI depends on the maturity of the organization because it conditions the use of BI to achieve the HRM strategy.

\section{BUSINESS INTELLIGENCE APPLIED TO HRM SUPPORTING BETTER DECISIONS MODEL PROPOSAL}

Based on previous literature and in the focus group results the model proposal consists of two dimensions HRIS modules, which includes: payroll, HR development, Self Service, Workflow and alerts and business process automation, and BI tools with the following set of variables: reporting, analysis, dashboard and measures/metrics. These variables are hypothesized to be associated with the process of decision making by the Human Resources Managers (Table 3).

The model shows the potential relation among HRIS, BI, and decision-making process in Human Resources management. It represents how BI tools can help to analyses employee's development and evaluate the efficiency of the recruiting and selection processes. It helps to assess how well the succession plans prepare the employees to assume key positions in the organization and monitor the progress of aligning employee goals with corporate goals. It also helps to analyze the cost-effectiveness of employee compensation systems.

\section{CONCLUSION}

Organizations that compete in today's knowledge-based economy recognize the growing importance of the data analysis accuracy in promoting competitiveness and helping to improve better organizations performance. The evolution of information technology has contributed to the increasing sophistication, and potential of BI applied to Human Resources Management, automating processes, and helping to analyze data to better decision making. These transformations are a paradigm shift in the HR function has to assume a new role as a partner of top management in decision-making on strategic issues.

In this context, Business Intelligence is a fundamental part of any organization, and HRM department's deals with particular information associated to the intellectual capital of the organization and needs to make it available efficiently and consistently to the other departments of the organization. For organizations, making use of BI is an effective means of reducing development time and supplementing a lack of in-house skills.

In this context this research main goal was to verify if BI is positively associated with HRM decision making and that also if it helps to predict HRM decisions in terms of future workforce planning and management and both of this hypothesis were validated by the sample of the conducted survey to 43 Portuguese Human Resources Manages and by focus groups which provided descriptions and examples of the practical dimensions that contributes for a better decision making process based on the BI tools in terms of workforce planning, workforce process analytics and measurement, talent management analytics and measurement and strategic alignment.

In summary, it is possible to say that BI facilitates the process of data analysis to make better decisions and helps organizations to achieve their strategic goals.

Acknowledgments: We want to acknowledge Talentia Software participation in this research. The principal analysis was developed using their HRM software and also for the help with the questionnaire. 
Table 3. Model BI applied to HRM supporting better decisions dimensions

\begin{tabular}{|c|c|}
\hline \multicolumn{2}{|r|}{ HRIS } \\
\hline Payroll & $\begin{array}{l}\text { Implementation and execution of the payroll systems to make it accurate and in time for } \\
\text { employees and also to give information for managers to make decisions about the retention and } \\
\text { progress of employees. }\end{array}$ \\
\hline HR Development & Analysis of the training and development processes to maximize employee performance. \\
\hline Self Service & Facilitation of the access of employees to their profiles and their data. \\
\hline Workflow \& Alerts & $\begin{array}{l}\text { Utilization of alerts for employees and managers to maintain tasks on time and several levels of } \\
\text { approvals. }\end{array}$ \\
\hline $\begin{array}{l}\text { Business Process } \\
\text { Automation }\end{array}$ & $\begin{array}{l}\text { A knowledgebase about job functions, positions, roles, and capabilities that are required to } \\
\text { drive the business performance. }\end{array}$ \\
\hline \multicolumn{2}{|l|}{ BI } \\
\hline Reporting & $\begin{array}{l}\text { Give business users the ability to access reports and continuously monitor organizational } \\
\text { performance }\end{array}$ \\
\hline Analysis & $\begin{array}{l}\text { KPIs are compared to strategic goals and objectives. The results are utilized to monitor, } \\
\text { further analyze, and act to improve performance. The advanced analytics subsystem enables } \\
\text { organizations to make informed decisions to align their goals and objectives, as well as } \\
\text { programs and budgets to the performance indicators. }\end{array}$ \\
\hline Dashboard & $\begin{array}{l}\text { Deliveries of performance indicators concerning human resources may include employee } \\
\text { retention, job satisfaction, compensation and rewards, employee training, accident levels, } \\
\text { employee absenteeism, and employee performance. }\end{array}$ \\
\hline Measures/Metrics & $\begin{array}{l}\text { Measure and analyze typical core HR processes, such as payroll, employee administration, time } \\
\text { management, and benefits. Analyze organizational structures, relationships, and attributes of } \\
\text { jobs and positions. }\end{array}$ \\
\hline \multicolumn{2}{|l|}{ Outputs } \\
\hline Cost Savings & Support HR professionals in all workforce cost-planning tasks. \\
\hline $\begin{array}{l}\text { Align individual and } \\
\text { organizational goals }\end{array}$ & $\begin{array}{l}\text { Ensure that all business activities are in line with the strategic goals of the organization. Help } \\
\text { Employee teams work toward common objectives, regardless of location. Use a balanced } \\
\text { scorecard framework, with predefined workforce scorecards that can be integrated into } \\
\text { department and individual management-by-objective documents to align employee goals with } \\
\text { corporate strategy. }\end{array}$ \\
\hline Recruit talent & $\begin{array}{l}\text { Monitor workforce demographics in line with recruitment and retention objectives. Analyze } \\
\text { the efficiency of the entire recruitment process lifecycle, understand, and prevent the drivers of } \\
\text { employee turnover. }\end{array}$ \\
\hline $\begin{array}{l}\text { Better decision } \\
\text { making }\end{array}$ & $\begin{array}{l}\text { Empower HR executives to develop effective strategies, providing access to a broad range of } \\
\text { workforce-related data to support accurate planning, facilitate simulated planning scenarios, } \\
\text { and enable continuous monitoring of actual performance relative to plan to achieve better } \\
\text { strategic decisions. } \\
\text { The organizations can adjust their goals and objectives, modify programs, and re-allocate } \\
\text { resources and funds. Performance measures, in essence, provide a feedback loop in the process } \\
\text { of business performance management. }\end{array}$ \\
\hline
\end{tabular}




\section{REFERENCES}

Pourshahid, A., Johari, I., Richards, G., Amyot, D., \& Akhigbe, O. S. (2014). A goal-oriented, business intelligence-supported decision-making methodology. Decision Analysis, 1(1). doi:10.1186/s40165-014-0009-8

Alhyasat, E. B., Al-Salt, J., Al-Dalahmeh, M., \& Amman, J. (2013). Data Warehouse Success and Strategic Oriented Business Intelligence: A Theoretical Framework. Journal of Management Research, 5(3), 169-184. doi:10.5296/jmr.v5i3.3703

Ball, K. S. (2001). The use of human resource information systems: A survey. Personnel Review, 30(6), 677-693. doi:10.1108/EUM0000000005979

Beadles, N. A. II, Lowery, C. M., \& Johns, K. (2005). The Impact of Human Resource Information Systems: An Exploratory Study in the Public Sector. IIMA. Communications of the IIMA., 5(4), 39-46. doi:10.1016/j. hrmr.2012.06.010

Becker, B. E., \& Huselid, M. A. (2006). Strategic human resource management: Where do we go from here? Journal of Management, 32(6), 898-925. doi:10.1177/0149206306293668

Elbashir, M. Z., Collier, P. A., \& Davern, M. J. (2008). Measuring the effects of business intelligence systems: The relationship between business process and organizational performance. International Journal of Accounting Information Systems, 9(3), 135-153. doi:10.1016/j.accinf.2008.03.001

Friedman, T. L. (2004). The World is Flat New York. Farrar, Straus, and Giroux.

Haines, V. Y., \& Petit, A. (1997). Conditions for Successful Human Resource Information Systems. Human Resource Management, 36(2), 261-275. doi:10.1002/(SICI)1099-050X(199722)36:2<261::AIDHRM7>3.0.CO;2-V

Hempel, P. S. (2004). Preparing the HR profession for technology and information work. Human Resource Management, 43(2-3), 163-177. doi:10.1002/hrm.20013

Hendrickson, A. R. (2003). Human resource information systems: Backbone technology of contemporary human resources. Journal of Labor Research, 24(3), 381-394. doi:10.1007/s12122-003-1002-5

Hustad, J. E., \& Munkvold, B. E. (2005). IT-supported competence management: A case study at Ericsson. Information Systems Management, 22(Spring), 78-88. doi:10.1201/1078/45099.22.2.20050301/87280.9

Isik, Ö., Jones, M. C., \& Sidorova, A. (2013). Business intelligence success: The roles of BI capabilities and decision environments. Information \& Management, 50(1), 13-23. doi:10.1016/j.im.2012.12.001

Jou, S., \& Ng, R. (2013). Introduction and the Changing Landscape of Business Intelligence. In M. T. Özsu (Ed.), Perspectives on Business Intelligence: Synthesis Lectures on Data Management (pp. 1-5). San Rafael, CA: Morgan \& Claypool Publishers. doi:10.2200/S00491ED1V01Y201303DTM034

Kapoor, B. \& Mihaylo. (2010). Business Intelligence and Its Use for Human Resource Management. The Journal of Human Resource and Adult Learning, 6(2), 21-30.

Kashive, N. (2011). Managing Today's Workforce: Human Resource Information System (HRIS), Its challenge and Opportunities. International Journal of Research in Finance \& Marketing, 1(6), 38-66.

Kavanagh, M. J., Gueutal, H. G., \& Tannenbaum, S. I. (1990). Human resource information systems: Development and application. Boston, MA: PWS-KENT Publishing Company; doi:10.1177/103841119002800422

Kesti, M. (2013, November). Human Capital Production Function. GSTF Journal on Business Review, 3(1), 1. doi:10.7603/s40706-013-0001-7

Laursen, G. H. N., \& Thorlund, J. (2010). Business analytics for managers: Take business intelligence beyond reporting. Hoboken, NJ: John Wiley and Sons.

Lengnick-Hall, M. L., \& Moritz, S. (2003). The Impact of e-HR on Human Resource Management. Journal of Labor Research, 24(3), 365-379. doi:10.1007/s12122-003-1001-6

Lippert, S. K., \& Swiercz, P. M. (2005). Human resource information systems (HRIS) and technology trust. Journal of Information Science, 31(5), 340-353. doi:10.1177/0165551505055399 
Lönnqvist, A., \& Pirttimäki, V. (2006). The Measurement of Business Intelligence. Information Systems Management, 23(1), 32-40. doi:10.1201/1078.10580530/45769.23.1.20061201/91770.4

Martinsons, M. G. (1994). Benchmarking human resource information systems in Canada and Hong Kong. Information \& Management, 26(6), 305-316. doi:10.1016/0378-7206(94)90028-0

Martinsons, M. G., \& Chong, P. K. (1999). The Influence of Human Factors and Specialist Involvement on Information Systems Success. Human Relations, 52(1), 123-152. doi:10.1177/001872679905200107

Mishra, A., \& Akman, I. (2010). Information Technology in Human Resource Management: An Empirical Assessment. Public Personnel Management, 39(3), 271-290. doi:10.1177/009102601003900306

Muryjas, P., \& Wawer, M. (2014). Business intelligence as a support in human resources strategies realization in contemporary organizations. Актуальні проблеми економіки, (2), 183-190.

Negash, S. (2006). Business Intelligence. Communications of the Association for Information Systems, 13(1), 177-195. Retrieved from http://aisel.aisnet.org/cais/vol13/iss1/15

O’Daniell, E. E. (1999). Energizing corporate culture and creating competitive advantage: A new look at workforce programs. Benefits Quarterly, 15(2), 18-25. PMID:10557894

Park, H. J., Gardner, T. M., \& Wright, P. M. (2004). HR practices or HR capabilities: Which matters? Insights from the Asia Pacific region. Asia Pacific Journal of Human Resources, 42(3), 260-273. doi:10.1177/1038411104045394

Shahzad, K. (2012). Vision or Psychic Prison. Business Intelligence Journal, 5(2), 207-213.

Singh, H. P., Jindal, S., \& Samim, S. A. (2011). The system, Role of Human Resource Information in Banking Industry of Developing Countries. International Journal of the Computer, the Internet and Management, 19(SP1), 44.1-44.4.

Skyrius, R., Kazakevičienė, G., \& Bujauskas, V. (2013). From Management Information Systems to Business Intelligence: The Development of Management Information Needs. International Journal of Artificial Intelligence and Interactive Multimedia, 2(3), 31-37. doi:10.9781/ijimai.2013.234

Snell, S. A., Stueber, D., \& Lepak, D. P. (2002). Virtual HR Departments: Getting out of the middle. In R. L. Heneman \& D. B. Greenberger (Eds.), Human resource management in virtual organizations (pp. 81-101). Greenwich, CT: Information Age Publishing.

Tannenbaum, S. I. (1990). Human Resource Information Systems: User Group Implications. Journal of Systems, 41(1), 27-32.

Tansley, C., \& Newell, S. (2007). A Knowledge-based View of Agenda-formation in the Development of Human Resource Information Systems. Management Learning, 38(1), 95-119. doi:10.1177/1350507607073028

Tansley, C., \& Watson, T. (2000). Strategic exchange in the development of human resource information systems (HRIS). New Technology, Work and Employment, 15(2), 108-122. doi:10.1111/1468-005X.00068

Teo, T. S., Lim, G. S., \& Fedric, S. A. (2007). The adoption and diffusion of human resources information systems in Singapore. Asia Pacific Journal of Human Resources, 45(1), 44-61. doi:10.1177/1038411107075402

Turban, E., Sharda, R., \& Delen, E. D. (2010). Decision support and business intelligence systems (9th ed.). Upper Saddle River, NJ: Prentice-Hall Press.

Turban, S. Aronson \& King (2008), Business Intelligence: A Managerial Approach, Pearson Prentice Hall, New Jersey.

Ulrich, D. (1997). Human Resource Champions. Boston: Harvard University Press.

Ulrich, D., Allen, J., Brockbank, W., Younger, J., \& Nyman, M. (2009). HR Transformation: Building human resources from the outside. New York: McGraw-Hill.

Vukší, V. B., Pejic-Bach, M., \& Popovič, A. (2013). Supporting performance management with business process management and business intelligence: A case analysis of integration and orchestration. International Journal of Information Management, 33(4), 613-619. doi:10.1016/j.ijinfomgt.2013.03.008 
Watson, H. J., \& Wixom, B. H. (2007, September). The Current State of Business Intelligence. Computer, 40(9), 96-99. doi:10.1109/MC.2007.331

Wu, D. D., Chen, S.-H., \& Olson, D. L. (2014). Business intelligence in risk management: Some recent progresses. Information Sciences, 256, 1-7. doi:10.1016/j.ins.2013.10.008

Maria José Sousa (Ph.D. in Management) is a University Professor and a research fellow at ISCTE/Instituto Universitário de Lisboa. Her research interests currently are public policies, information science, innovation and management issues. She is a best seller author in ICT and People Management and has co-authored over 70 articles and book chapters and published in several scientific journals (e.g. Journal of Business Research, Information Systems Frontiers, European Planning Studies, Systems Research, and Behavioral Science, Computational and Mathematical Organization Theory, Future Generation Computer Systems and others), she has also organized and peer-reviewed international conferences, and is the guest-editor of several Special Issues. She has participated in several European projects of innovation transfer and is also External Expert of COST Association - European Cooperation in Science and Technology and President of the ISO/TC 260 - Human Resources Management, representing Portugal in the International Organization for Standardization.

Ivo Dias is an Assistant Professor at Universidade Europeia. He received his Ph.D. degree in Organizational and Economics Sociology from ISEG - Lisbon University and his research is in the fields of human resources and economy. He has published several research papers and has extensive practical experience in public and private academies and organizations. He also participates in research projects at the European University, namely the project PASC (Associations Platform of Civil Society), and e-work and a collaborator of the ISCSP - Lisbon University in the development of the Strategic Plan for the Municipality of Santa Cruz (Madeira). 